\title{
The Application of Small-Scale and Large-Scale Wind Turbines in Kerman, Iran; A Case Study
}

\author{
Ighball Baniasad Askari \\ Department of Mechanical \\ Engineering, Faculty of \\ Engineering, University \\ of Zabol, Iran. \\ Eghball_baniasad@yahoo.com
}

\author{
Lina Baniasad Askari \\ Faculty of Engineering, \\ University of Economic Sciences, \\ Tehran, Iran. \\ Linabaniasad@yahoo.com
}

\author{
Mohammad Mehdi Kaykhah \\ Department of Mechanical \\ Engineering, Faculty of \\ Engineering, University \\ of Zabol, Iran. \\ mmkkaykha@yahoo.com
}

\begin{abstract}
Wind data collected of the three synoptic sites for the period of Jul 2006 to Jun 2008 at the height of 40 $m$ has been used to study the wind characteristics, monthly and annual wind energy potential for three agricultural districts in Kerman ( $\left.30^{\circ} 15 / \mathrm{N}, 56^{\circ} 58 / \mathrm{E}\right)$, Iran. Two statistical methods (Meteorological and Weibull) have been applied to determine the wind characteristics. Wind energy density, mean wind speeds and wind speed directions have been investigated. A technical assessment has been done and the electricity generation from five different wind turbines having capacity of $(26 \mathrm{~kW}, 100 \mathrm{~kW}, 300 \mathrm{~kW}, 600 \mathrm{~kW}$ and 660 $\mathrm{kW}$ ) has been calculated. The results show that all the locations studied are not suitable for electric wind application in a large-scale.
\end{abstract}

Keywords - Wind turbine, wind characteristics, Weibull parameters, Wind directions, Technical assessment

\section{INTRODUCTION}

There are many remote or off-grid locations around the world, especially in developing countries that rely on diesel generators for their power supply. However, this conventional generation depends on the availability of fossil fuel and it doesn't environmentally friendly. Therefore, the renewable energy systems can be used as an alternative to get rid of these economic and environmental problems to supply the energy demands for those particular areas in a sustainable way.

Wind energy is a clean energy which has the potential to meet a significant proportion of the world's energy requirements. A remarkably rapid growth in the wind energy has been recorded over the past two decades; expanding at annual rate of between 25 to $35 \%$ [1]. The fast pace of wind turbine technology developments is the main factor due which wind energy has become competitive with other fuel based generation resources. Since the cost of wind turbine generators (WTGs) has been reduced to a great extent, installation of WTGs, as fuel savers, is going to be environmentally friendly and economically justified especially in the countries with high fuel prices. Presently, thousands of renewable energy systems exist worldwide, providing power to small, remote grid-independent or stand-alone applications. Using this alternative source of energy reduces the need for combustion of fossil fuels and the consequent $\mathrm{CO}_{2}$ emission which is the principal cause of the greenhouse effect and global warming. Renewable energy systems consisting of different energy sources (solar, wind, etc) are the only way to generate electricity in some regions of developing countries $[1,2]$.

Hannes Weigt [3] investigated the extent to which wind energy can replace fossil capacities in Germany. In that work, the potential savings due to wind energy was also assessed. The German market was modeled with and without wind input to estimate the net savings of fossil fuels in a typical time Period. From the results of that survey it was found that the cost-saving potential for electricity production is quite significant and exceeds the subsidies. Aynur and Figen [4] analyzed the wind characteristics to evaluate the wind energy potential of six locations in Turkey. Their study presents the maximum value of monthly mean wind speed, mean annual value of Weibull parameters, the most windward directions and the annual mean specific wind power densities for that six locations. A wind energy potential assessment in Naxos Island, Greece has been done by Fyrippis et al [5]. In that work, the wind characteristics were statistically analyzed using the 
Weibull and Rayleigh distribution functions. Finally, the site they have considered was found to have a very pronounced wind potential. Wind energy potential of the capital of Iran, Tehran has been investigated by Keyhani et al. [6] using the statistical data of eleven years' wind speed measurements. Two statistical methods of meteorological and Weibull were assessed to evaluate the wind energy potential.

Sahin et al. [7] have been investigated the wind energy potential of the eastern Mediterranean region using hourly wind data. They have identified the mean power density of the different areas of their region of study and finally they have determined the best locations in terms of wind power generation. The wind power potentials of the Pearl River Delta (PRD) region (China) have been statistically analyzed based on the hourly measured wind speed data in four islands by Zhou et al. [8]. In that study the wind power and operating possibilities of these locations have been investigated based on the Weibull function. Because the wind power at those different sites varied significantly, a careful attention to the wind conditions as well as the site terrains in choosing the wind farm sites was suggested as the result of that study.

Because the fuel price is highly subsidized in Iran, for many years electrical energy has been produced using diesel generation systems, especially for agricultural consumptions. But lately, the government has decided to eliminate the fuel price subsidies, and this is expected to increases the cost of the diesel generation systems. The increasing consumption and, consequently, the cost of conventional fuels coupled with environmental considerations have led to the development of renewable energy resources in Iran. According to the previous investigations, Iran enjoys only a moderate supply of wind power, with some regions having continuous air flows with sufficient energy to produce electricity (the average wind velocity in such regions is measured at about $5 \mathrm{~m} / \mathrm{s}$ ). The potential capacity of wind power is figured at about $6500 \mathrm{MW}$ for the country, mostly in the eastern sections [9].

In the present paper, three agriculturally fertile districts of the largest province of Iran Kerman Province have been chosen as the study area. The three regions described are Rafsanjan $\left(30^{\circ} 25^{/} \mathrm{N}, 55^{\circ} 54 / \mathrm{E}\right)$, Shahre-Babak $\left(30^{\circ} 6^{/} \mathrm{N}, 55^{\circ} 8 / \mathrm{E}\right)$ and Orzuye $\left(28^{\circ} 23^{\prime} \mathrm{N}, 56^{\circ} 20^{\mathrm{E}}\right)$, which are known as three agricultural poles of Kerman in the productions like pistachio, grain, wheat and having the vast farms of cotton and watermelon. For many years, diesel and electrical water pumps have been used as the water pumping systems. Besides, a great deal of fuel and electricity has been consumed as the energy sources of pistachio and corn dryer systems. But, Iran has decided to remove its fuel price subsidies. So, the application of renewable energy systems is the best alternative to reduce the energy generation expenses.

\section{METHODOLOGY AND MATERIALS}

\section{A. Wind data}

For three locations of the present study, wind data were obtained from the Iran renewable energy organization (SANA). The anemometer height was $40 \mathrm{~m}$, from the July of 2006 to Jun of 2008 , recorded at the time intervals of $10 \mathrm{~min}$. The three locations investigated are Rafsanjan $\left(30^{\circ} 25^{\prime} \mathrm{N}, 55^{\circ} 54 / \mathrm{E}, 1600 \mathrm{~m}\right)$, Shahre-Babak $\left(30^{\circ} 6 / \mathrm{N}, 55^{\circ} 8 / \mathrm{E}, 1700 \mathrm{~m}\right)$, and Orzuye $\left(28^{\circ} 23^{\prime} \mathrm{N}, 56^{\circ} 20^{\prime} \mathrm{E}, 1800 \mathrm{~m}\right)$. Table.1 shows the seasonal mean wind speeds of three study areas. Generally, Rafsanjan in all four seasons of year had the most strong wind speeds as compare to those another two locations. In contrast, Orzuye had the poorest wind speed records during the year. It can be seen that Rafsanjan in spring had higher mean wind speeds, peaking in March and its winter had the lower mean wind speeds of $5.05 \mathrm{~m} / \mathrm{s}$. Both spring and summer months had a higher prevalence of stronger wind speeds, with lower wind speeds recorded in fall for Shahr-Babak. As for the Orzuye, The highest and lowest wind speeds occurred in spring $(4 \mathrm{~m} / \mathrm{s})$ and winter $(3.13 \mathrm{~m} / \mathrm{s})$, respectively.

Table. 1

Seasonal ${ }^{1}$ mean wind speeds $(\mathrm{m} / \mathrm{s})$

\begin{tabular}{ccccc}
\hline Location & Winter & Spring & Summer & Fall \\
\hline Rafsanjan & 5.05 & 5.95 & 5.37 & 5.24 \\
Shahr- & 3.96 & 4.76 & 4.75 & 3.78 \\
Babak & 3.13 & 4.01 & 3.70 & 3.24 \\
Orzuye & & & & \\
\hline
\end{tabular}

An investigation has been done to calculate the daily variation of mean wind speeds of the study regions. Figs. 1 to 3 show the mean wind speeds of the study areas for three typical months of the year. As can be seen from Figs.1 to 3, Rafsanjan, had a regular variation in mean wind speeds during the

a Winter is defined as January, February, and December; Spring as March, April, and May, Summer as June, July, and August; Fall as September, October, November 
day-times. Unlike Rafsanjan, Shahr-Babak had a steep fall and rise in wind speeds. Shahrbabak, on the whole, had an increase in mean wind speeds from hour $8 \mathrm{AM}$ to $18 \mathrm{PM}$. The results have been shown that during the months June to August, Orzuye had the most variations in the mean wind speeds; from 1.55 to $7.22 \mathrm{~m} / \mathrm{s}$ for August.

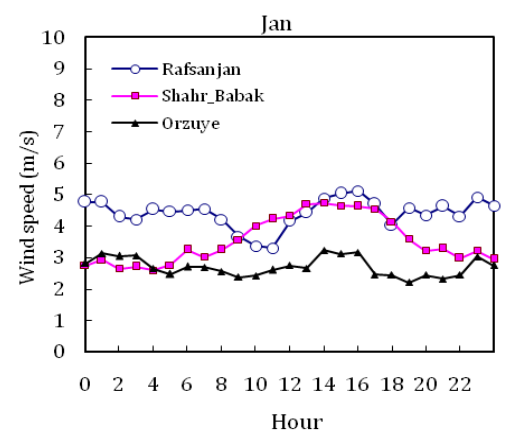

Fig.1. Mean wind speed) for three study area, January

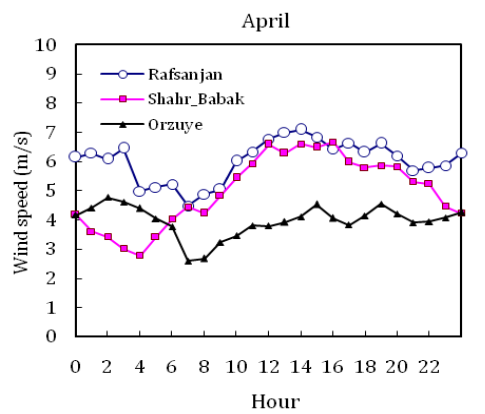

Fig.2. Mean wind speed) for three study area, April

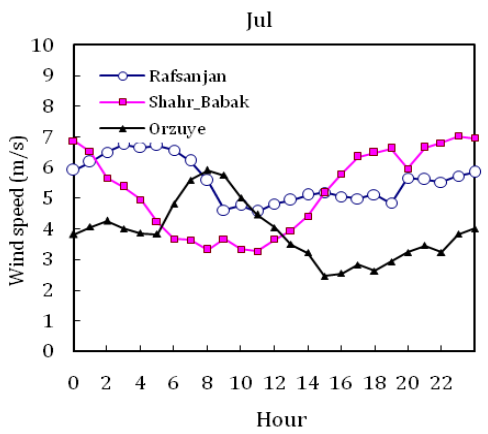

Fig.3. Mean wind speed) for three study area, July

\section{B. Weibull distribution of wind speed}

If wind speed distribution in any location is known, the power density belonging to the site can be easily obtained. To explain the stochastic behavior of a wide range wind speed, it is necessary to have a few key parameters. Statistical functions are usually used to describe the wind speed variations. The simplest and most common method for the procedure is to use a probability distribution function. There are several probability density functions, which can be used to describe the wind speed frequency curve. The Weibull distribution function is one of the normally used functions to illustrate the wind speed distributions:

$$
\mathrm{f}(\mathrm{v})=\left(\frac{\mathrm{k}}{\mathrm{c}}\right)\left(\frac{\mathrm{v}}{\mathrm{c}}\right)^{\mathrm{k}-1} \cdot \exp \left\lfloor-\left(\frac{v}{\mathrm{c}}\right)^{\mathrm{k}}\right\rfloor
$$

where $f(v)$ is the distribution probability of wind speed $v, c$ and $k$ are the Weibull scale and shape parameter, respectively, which can provide great flexibility of fitting the distribution function to the measured values with different behaviors. The dimensionless shape parameter of ' $k$ 'shows how the wind distribution peaked is, and ' $c$ ' is the dimensionless scale parameter that shows how 'windy' a wind site under consideration is.

The following equations are used to calculate the Weibull parameters:

$$
\begin{aligned}
& k=\left(\frac{\sigma}{\bar{v}}\right)^{-1.086}(1 \leq k \leq 10) \\
& \mathrm{c}=\frac{\bar{v}}{\Gamma\left(1+\frac{1}{\mathrm{k}}\right)}
\end{aligned}
$$

where the average wind speed, $\bar{v}$ and the variance, $\sigma^{2}$, of wind velocity are calculated using equations (6) and (7), respectively.

$$
\bar{v}=\frac{1}{\mathrm{n}} \sum_{\mathrm{i}=1}^{\mathrm{N}} v_{\mathrm{i}}
$$

$\sigma^{2}=\left\lfloor\frac{1}{\mathrm{n}-1} \sum_{\mathrm{i}=1}^{\mathrm{N}}\left(v_{i}-\bar{v}\right)^{2}\right\rfloor$

In addition, the characteristic speeds of the studied site ( $v_{\mathrm{mp}}$ and $\left.v_{\mathrm{Max}, \mathrm{E}}\right)$ are calculated by the following relations:

$$
\begin{aligned}
& v_{\mathrm{mp}}=\mathrm{c}\left(1-\frac{1}{\mathrm{k}}\right)^{1 / \mathrm{k}} \\
& v_{\mathrm{Max}, \mathrm{E}}=\mathrm{c}\left(1+\frac{2}{\mathrm{k}}\right)^{1 / \mathrm{k}}
\end{aligned}
$$

where $v_{m p}$ is the most probable wind speed and $v_{\text {Max }, E}$ is wind speed carrying the maximum energy. The average wind power density of site based on Weibull probability density function can be expressed as:

$$
\frac{\mathrm{P}}{\mathrm{A}}=\frac{1}{2} \rho \cdot \mathrm{c}^{3} \cdot \Gamma\left(1+\frac{3}{\mathrm{k}}\right)\left(\mathrm{W} / \mathrm{m}^{2}\right)
$$




\section{Meteorological Method}

The specific power available in a cross-sectional area (A) perpendicular to the wind stream moving at speed $\mathrm{V}(\mathrm{m} / \mathrm{s})$ is calculated by using the following equation: [10]

$$
\mathrm{p}=\frac{1}{2} \rho \mathrm{V}^{3}
$$

where $\rho$ is the standard air density at sea level with a mean temperature of $15^{\circ} \mathrm{C}$ and a pressure of $1 \mathrm{~atm}$ $(1.225 \mathrm{~kg} / \mathrm{m} 3)$ and $\mathrm{V}$ is the mean wind speed $(\mathrm{m} / \mathrm{s})$.

$6.5 / \mathrm{km}$, and $\mathrm{g}=9.81 \mathrm{~m} / \mathrm{s}^{2}$ is the gravitational acceleration.

\section{RESULTS AND DISCUSSIONS}

\section{A. Probability density functions}

The average annual variation of observed and Weibull wind speed frequencies for three locations of the study have been determined using the two years wind speed data. As a sample the results of the calculations for Rafsanjan has been depicted inFig.4. It can be clearly seen that Weibull function fits the observed distribution reasonably well in the relevant wind range. According to the figure, for Rafsanjan the peak frequencies of 14.85 and $13.5 \%$ occurred at wind speeds of 4 and $5 \mathrm{~m} / \mathrm{s}$, respectively. Additionally, the frequency of wind speeds of less than and equal $3 \mathrm{~m} / \mathrm{s}$ are approximately $26 \%$ for Rafsanjan. However, the results of the study show that this value is 43 and $53 \%$ for Shahr-Babak and Orzuye, respectively. For both Shahr-Babak and Orzuye, peak frequencies stood at wind speeds of 4 and $3 \mathrm{~m} / \mathrm{s}$, respectively.

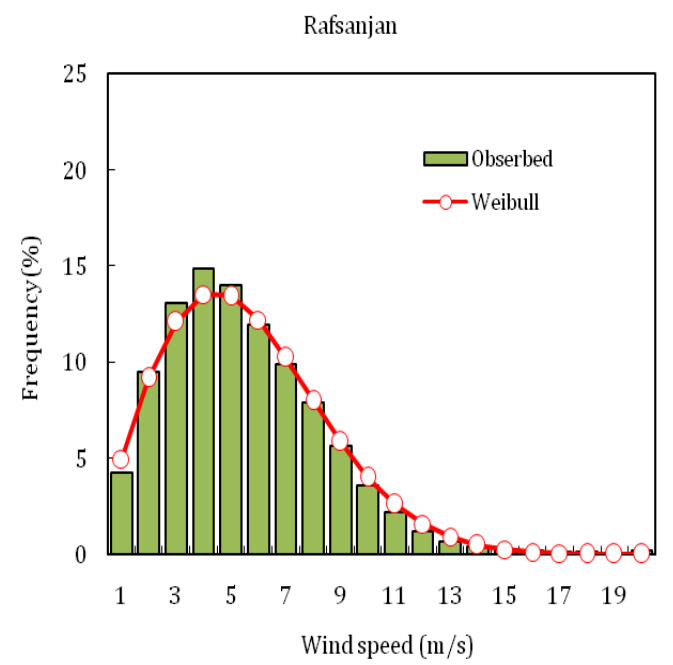

Fig.4. Observed and calculated wind speed frequencies

\section{B. Wind power density and energy}

The wind speed data for three locations (Rafsanjan, Shahr-Babak and Orzuye) have been analyzed taking into account the monthly and annual variations. For Rafsanjan, the variation of Weibull parameters ( $k$ and $c)$, mean wind speeds, and wind energy during the period of Jun 2006 to Jul 2008 is listed in Tables 2 . Table 2 shows that for Rafsanjan Weibull shape parameter $k$ varies between 2.14 and 3.66 , while scale parameter $c$ varies between 5.00 and $6.80 \mathrm{~m} / \mathrm{s}$. The maximum and minimum value of the monthly mean speed at $40 \mathrm{~m}$ is 6.23 and $4.43 \mathrm{~m} / \mathrm{s}$, respectively.

The results of two other regions of the study have shown that the shape parameter $\mathrm{k}$ has a minimum value of 2.04 at Shahr-Babak in February and it has a maximum value in June. The highest and lowest of values of $\mathrm{C}$ are found in July and November, respectively, for Shahr-Babak. As for Orzuye it was found that this region has a yearly average of 4.88 $\mathrm{m} / \mathrm{s}$ for $\mathrm{C}$; having a minimum in November and a maximum in July. Also, among three locations of the study, Orzuye with an annual average value of 34.03 $k \mathrm{Wh} / \mathrm{m}^{2}$ has the minimum wind energy.

Table. 2

Monthly variation of Weibull parameters and characteristic speeds (at $40 \mathrm{~m}$ height) and wind power energy in Rafsanjan

\begin{tabular}{ccccc|c}
\hline \multicolumn{5}{c}{ Weibull } & Meteorological \\
\hline Month & $k$ & $c(\mathrm{~m} / \mathrm{s})$ & $v_{\text {mean }}$ & $\begin{array}{c}\text { Energy } \\
\left(\mathrm{kWh} / \mathrm{m}^{2}\right)\end{array}$ & $\begin{array}{c}\text { Energy } \\
\left(\mathrm{kWh} / \mathrm{m}^{2}\right)\end{array}$ \\
\hline Jan & 2.14 & 5.01 & 4.43 & 71.05 & 68.72 \\
Feb & 2.50 & 6.33 & 5.61 & 115.02 & 113.43 \\
Mar & 2.84 & 7.06 & 6.23 & 160.23 & 161.61 \\
Apr & 2.97 & 6.79 & 6.06 & 138.64 & 139.69 \\
May & 3.27 & 6.09 & 5.46 & 99.61 & 97.65 \\
Jun & 3.66 & 6.11 & 5.51 & 94.23 & 92.82 \\
Jul & 2.58 & 5.87 & 5.22 & 113.15 & 101.59 \\
Aug & 2.65 & 6.27 & 5.57 & 116.47 & 117.22 \\
Sep & 3.40 & 6.18 & 5.55 & 99.49 & 98.40 \\
Oct & 3.10 & 5.80 & 5.17 & 84.38 & 86.19 \\
Nov & 2.13 & 5.49 & 4.89 & 83.40 & 88.72 \\
Dec & 2.93 & 5.35 & 4.77 & 76.29 & 71.55 \\
\hline Ave & 2.85 & 6.03 & 5.37 & 104.33 & 103.13 \\
\hline
\end{tabular}

Wind energy potential, calculated by EQ (8), and mean wind speeds of the three locations at height of $40 \mathrm{~m}$ are shown in Figs 5 and 6, respectively. It is clearly evidence (Fig. 5) that Rafsanjan for all months had the highest amount of wind energy potential as compare to those two other areas. Compared to Rafsanjan and Shahr-Babak, Orzuye had a poor wind energy potential pattern of less than $80 \mathrm{~W} / \mathrm{m} 2$ for all 
months of the year. Besides, for Rafsanjan the wind energy potential rose sharply from January to March; hitting a peak of $215 \mathrm{~W} / \mathrm{m} 2$. However, for next two months (May and June), wind energy potential declined steeply, reaching values of $133 \mathrm{~W} / \mathrm{m} 2$. This was followed by a 50\% drop in energy density between the months Aug and Dec for Rafsanjan. Although, Shahr-babak energy density was much lower, it was very similar to that of the Rafsanjan, declining or increasing almost at a same trend. As for Shahr-babak, there was a sudden increase in wind energy potential; rising from $50 \mathrm{~W} / \mathrm{m} 2$ in January to more than $120 \mathrm{~W} / \mathrm{m} 2$ in April. However, this followed by a decrease of $47 \%$ for next two months. Furthermore, Shahr-babak wind energy density had a sharp increase of $60 \%$ from Jun to July, remained steady to Aug and followed by a steep decline in October. As for Orzuye, the wind energy potential had no considerable fluctuations; varied between 19.60 $\mathrm{W} / \mathrm{m} 2$ in January and $75.46 \mathrm{~W} / \mathrm{m} 2$ in June. Generally, except June, its summer and spring wind energy density was higher than other two cold seasons.

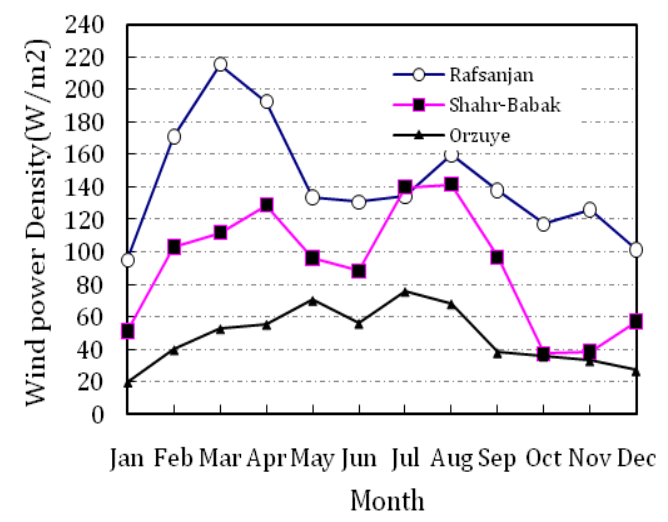

Fig.5. Wind power density at height of $40 \mathrm{~m}$

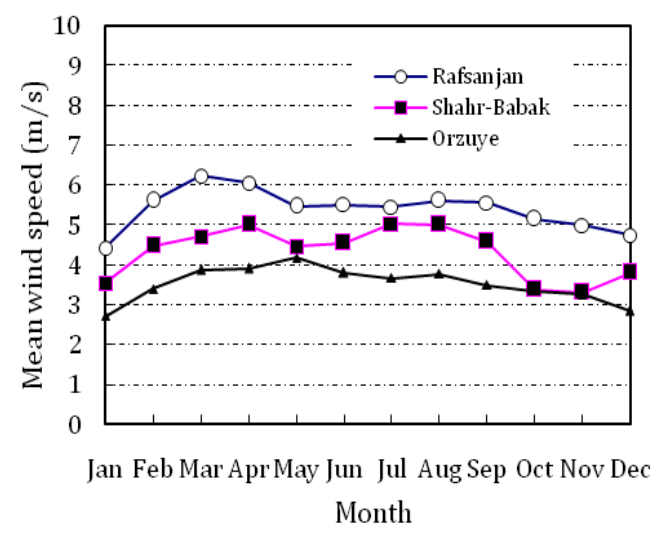

Fig.6. Mean wind speed at height of $40 \mathrm{~m}$

\section{Wind direction}

A wind rose is a diagram that shows the distribution of wind directions and speeds at a specific location over a specified time period. The prediction of wind direction is important because of the several reasons; to conduct wind energy researches, displays the impact of geographical features on the wind, to make proper and technically justified decisions when planning the installation and the micrositting of a wind turbine or a wind farm.

The wind direction is illustrated in polar diagrams and is measured clockwise in degrees. The circle $\left(360^{\circ}\right)$, which represents the cardinal points, is divided in 36 sectors and each of them covers an arc of $10^{\circ}$. The annual wind rose based on time and energy (The duration of the stillness as a fraction of time and energy) during the period Jun 2006 to Jul 2008 at the three locations of the study is shown in figures 7 to 9 . Fig. 7 shows that the highest percentages of the available wind energy for wind speeds of more than and equal to $3 \mathrm{~m} / \mathrm{s}$ at Rafsanjan were $12 \%$ and $11 \%$ blowing from 150 and $230^{\circ}$, which correspond to the South-South-East and South-West, respectively.

A similar analysis has been done to determine the percentage of calm conditions, where the wind speed is less than or equal to $3 \mathrm{~m} / \mathrm{s}$. As for Rafsanjan, the results shown that the high percentage of calm conditions is found at the directions between 240 to $320^{\circ}$ which correspond to the West-South-West and West-NorthWest, respectively. Also, it is noticeable that the minimum percentage of low condition is occurred at $150^{\circ}$; the direction with highest percentages of the available wind energy.

Figure 8 correspond to the percentages of the available wind energy for Shahr-Babak, respectively. As can be seen from this figure, directions with the high percentages of available wind energy are 260 and $80^{\circ}$. The results show that these two directions with the high percentages of available wind energy (260 and $80^{\circ}$ ) have a low percentage of calm conditions; 3 and $2.25 \%$, respectively. As for Shahr-Babak, the high percentage of calm conditions is obtained between the directions of 100 and $140^{\circ}$ (East-South-East and South-East).

The wind rose diagram of available wind energy for Orzuye is shown in Fig.9. As can be seen from this figure, the highest percentage of available wind energy is occurred at the directions of 20 and $220^{\circ}$. The results of investigation on the Orzuye calm conditions shows that the high percentage of calm conditions with wind speeds of less than $3 \mathrm{~m} / \mathrm{s}$ is found at those directions with 
highest percentage of available wind energy (20 and $\left.220^{\circ}\right)$. It is worthy of notice since we can come into this conclusion that the scatter in distribution of wind speed (sudden decreases in the wind speeds) in Orzuye is high as compared to those other two locations of the study.

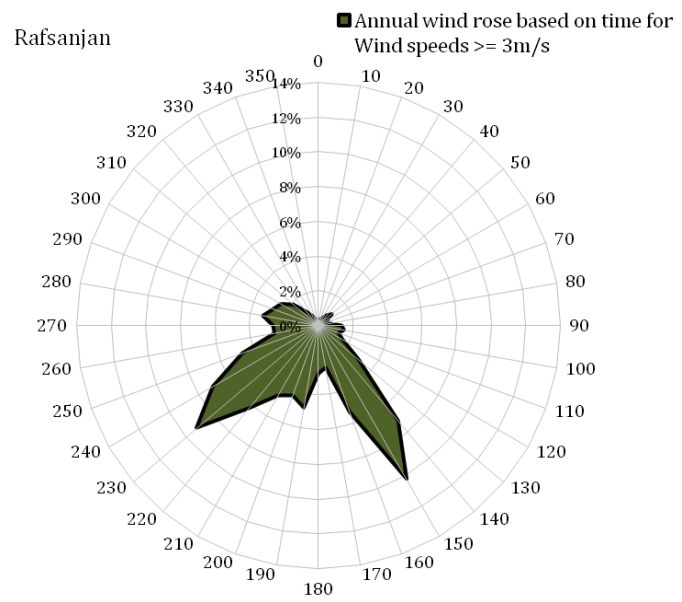

Fig.7. Rafsanjan annual wind rose based on energy

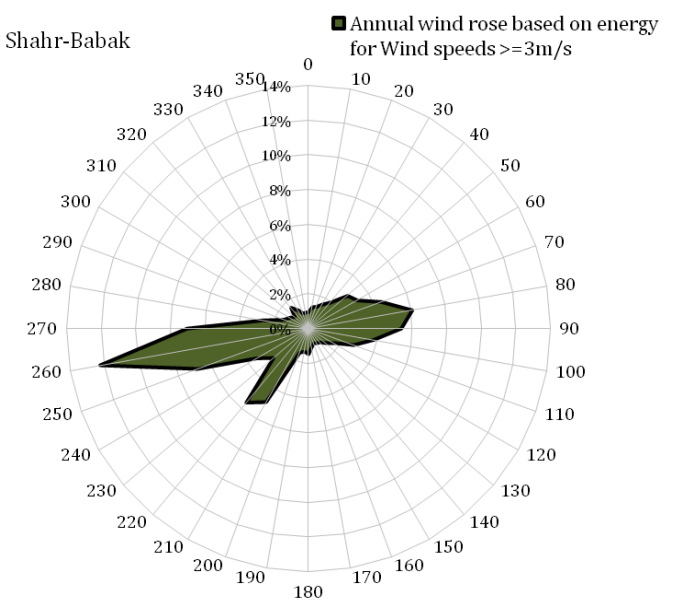

Fig.8. Shahr-Babak annual wind rose based on energy

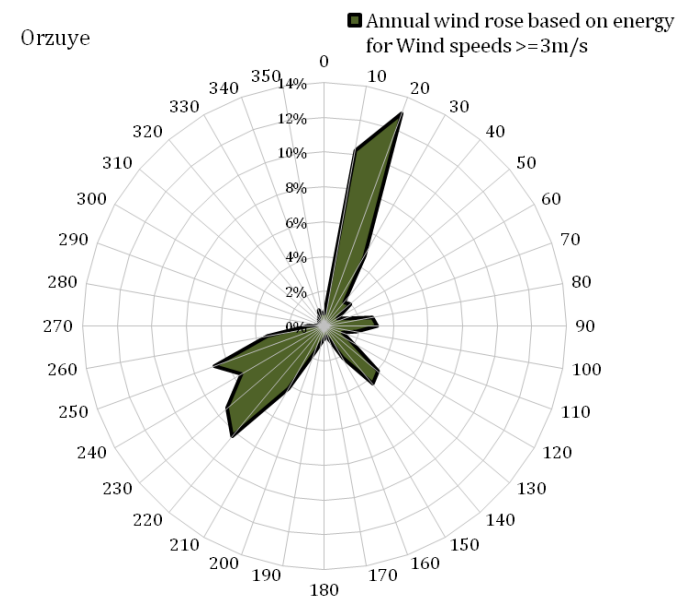

Fig.9. Orzuye annual wind rose based on energy

\section{Energy output from selected wind turbines}

A technical assessment has been done in order to determine the annual average wind energy produced by five different commercial wind turbines, one of which is made in Iran (S-47 $660 \mathrm{~kW}$ ). The main characteristics of wind turbines have been represented in Table. 3. As can be seen the rated powers of wind turbines are $26 \mathrm{~kW}, 100 \mathrm{~kW}, 300 \mathrm{~kW}$, $600 \mathrm{~kW}$ and $660 \mathrm{~kW}$; with two different cut in speeds of 3 and $4 \mathrm{~m} / \mathrm{s}$.

Table. 3

Characteristics of five different commercial wind turbines

\begin{tabular}{cccccc}
\hline Characteristic & $\begin{array}{c}\text { Rated } \\
\text { power } \\
(\mathrm{kW})\end{array}$ & $\begin{array}{c}\text { Cut in } \\
\text { speed } \\
(\mathrm{m} / \mathrm{s})\end{array}$ & $\begin{array}{c}\text { Rated } \\
\text { speed } \\
(\mathrm{m} / \mathrm{s})\end{array}$ & $\begin{array}{c}\text { Cut } \\
\text { off } \\
\text { speed } \\
(\mathrm{m} / \mathrm{s})\end{array}$ & $\begin{array}{c}\text { Rotor } \\
\text { Diameter(m) }\end{array}$ \\
\hline $\begin{array}{c}\text { Energie PGE } \\
(\text { PGE26) }\end{array}$ & 26 & 4 & 11 & 15 & 11 \\
\hline $\begin{array}{c}\text { Fuhrlaende } \\
(\text { FL100) }\end{array}$ & 100 & 3 & 14 & 25 & 21 \\
\hline $\begin{array}{c}\text { Bonus } \\
(300 \text { MKII) }\end{array}$ & 300 & 4 & 14 & 25 & 33 \\
\hline $\begin{array}{c}\text { De-Wind } \\
(\text { DW600-46) }\end{array}$ & 600 & 3 & 12 & 22 & 46 \\
\hline $\begin{array}{c}\text { S-47 660 kW } \\
\text { (260 }\end{array}$ & 660 & 4 & 15 & 25 & 47
\end{tabular}

The Mean output power, annual energy production, capacity factor and operation hours of each selected five wind turbines has been calculated for three locations of the study at hub height of $40 \mathrm{~m}$ (Table.4). As it might have been expected Rafsanjan and Orzuye had the maximum and minimum wind energy for each wind turbine, respectively.

Capacity factor is the average power output of a wind turbine divided by the total wind turbine capacity. Table.4 reveals that among five selected wind turbines, Energie PGE (PGE 26) has the highest capacity factor. Because of the poor wind speeds, wind turbines with high rated power have not been capable to produced power for many times of the year. So, for three locations of the study wind turbines with high rated powers had low capacity factors. The effect of wind turbine cut in speeds on their operation hours is one of the other outcomes. Table.4 shows that the difference between the yearly operation hours of wind turbines with cut wind speed of $3 \mathrm{~m} / \mathrm{s}$ and $4 \mathrm{~m} / \mathrm{s}$ are approximately $14 \%$, $33 \%$ and $39 \%$ for Rafsanjan, Shahr-Babak and Orzuye, respectively. A comparison between the Iranian wind turbine of S-47 $660 \mathrm{~kW}$ and De-Wind 
$600 \mathrm{~kW}$ (Fig.15) shows that for the wind speeds of between 3 and $13 \mathrm{~m} / \mathrm{s}, \mathrm{S}-47660 \mathrm{~kW}$ generates less energy than De-Wind $600 \mathrm{~kW}$. This results in total yearly wind energy produced by S-47 $660 \mathrm{~kW}$, which for three locations of the study; this wind turbine has generated less wind energy as compared to De-Wind $600 \mathrm{~kW}$.

Table.4

Mean output power, annual energy production, capacity factor and operation hours of four different wind turbines for three locations

\begin{tabular}{cccccc}
\hline $\begin{array}{c}\text { Wind } \\
\text { turbine }\end{array}$ & Location & $\begin{array}{c}\text { Mean } \\
\text { output } \\
\text { power } \\
\text { (kW) }\end{array}$ & $\begin{array}{c}\text { Capacity } \\
\text { factor } \\
(\%)\end{array}$ & $\begin{array}{c}\text { Annual } \\
\text { production } \\
\text { (kWh/yr) }\end{array}$ & $\begin{array}{c}\text { Hours of } \\
\text { operation } \\
\text { (hr/yr) }\end{array}$ \\
\hline $\begin{array}{c}\text { PGE26 } \\
\text { kW }\end{array}$ & Raf & 10.6 & 40.8 & 93,006 & 7,197 \\
& Sh-B & 6.6 & 25.2 & 57,389 & 5,148 \\
\hline FL100 & Orz & 4.1 & 15.8 & 36,093 & 4,767 \\
kW & Raf & 22 & 21.9 & 191,912 & 8,204 \\
& Shr-B & 13 & 13.2 & 115,747 & 6,847 \\
\hline B-300 & Orz & 7 & 6.61 & 57,893 & 6,620 \\
kW & Raf & 60 & 20 & 526,380 & 7,197 \\
& Sh-B & 36 & 12 & 314,904 & 5,148 \\
& Orz & 18 & 5.91 & 155,355 & 4,767 \\
\hline DeW600 & Raf & 117 & 19.5 & $1,026,070$ & 8,199 \\
kW & Sh-B & 71 & 11.9 & 625,488 & 6,847 \\
& Orz & 37 & 6.17 & 324,508 & 6,620 \\
\hline S-47 & Rafs & 116 & 17.6 & $1,016,995$ & 7,136 \\
& Sh-B & 70 & 10.5 & 606,856 & 5,114 \\
& Orz & 33 & 5.07 & 293,328 & 4,757 \\
\hline & & & & & \\
\hline
\end{tabular}

\section{CONCLUSION}

Two statistical methods (Meteorological and Weibull) have been applied to determine the monthly wind energy and density of three agricultural districts in Kerman, Iran . The main outcomes drawn from this investigation into the wind characteristics can be summarized as follows:

- Among three locations, Rafsanjan had the lowest number of hours with poor wind speeds of less than 3 or $4 \mathrm{~m} / \mathrm{s}$. And Orzuye with 5800 hours with wind speeds of less than $3 \mathrm{~m} / \mathrm{s}$ had the higher number of poor wind speeds during the year.

- The frequency of wind speeds of less than and equal to $3 \mathrm{~m} / \mathrm{s}$ are approximately 26\%, 43 and $53 \%$ for Rafsanjan, Shahr-Babak and Orzuye, respectively.
- All three areas of the study have their maximum value of mean wind speeds in spring.

- The maximum value of monthly mean wind speed is determined as $6.23 \mathrm{~m} / \mathrm{s}$ at Rafsanjan in March and a minimum value of $2.71 \mathrm{~m} / \mathrm{s}$ is occurred at Orzuye in Jan. The values of annual mean wind speed is obtained 5.4, 4.32 and $3.52 \mathrm{~m} / \mathrm{s}$ at Rafsanjan, Shahr-Babak and Orzuye, respectively.

- The annual highest values of Weibull shape parameter $\mathrm{k}$ and scale parameter $\mathrm{c}$ are found at Rafsanjan and the inverse is true for Orzuye.

- The highest percentages of the available wind energy for wind speeds of more than and equal to $3 \mathrm{~m} / \mathrm{s}$ are calculated at South-South-East (SSE) and South-West (SW) for Rafsanjan. As for ShahrBabak, the most probable wind directions of East-South-East (ESE) and South-East (SE) are obtained as directions with highest percentages of the available wind energy.

- As for Orzuye, the high percentage of calm conditions with wind speeds of less than $3 \mathrm{~m} / \mathrm{s}$ is found at those directions with highest percentage of available wind energy. This reveals the scatter in distribution of wind speed (sudden decreases in the wind speeds) in Orzuye.

- Among five selected wind turbines, a wind turbine (PGE 26) with the minimum rated power has the highest capacity factor. Because of the poor wind speeds, wind turbines with high rated power have not been capable to produced power for many times of the year.

- The difference between the yearly operation hours of wind turbines with cut wind speed of 3 $\mathrm{m} / \mathrm{s}$ and $4 \mathrm{~m} / \mathrm{s}$ has been calculated as approximately 14\%, 33\% and 39\% for Rafsanjan, Shahr-Babak and Orzuye, respectively.

Generally, because the chances of having wind speeds less than $3 \mathrm{~m} / \mathrm{s}$ are high and the wind speed range for electricity generation is within 2.71-6.28 $\mathrm{m} / \mathrm{s}$, all the locations studied are not suitable for electric wind application in a large-scale. Besides, it could be predicted that because of the scatter in wind speeds, the required storage capacity and consequently the investment costs will be high if a stand-alone wind/bat system would be chosen at three locations of the study. Since, another option which worth to study about could be a gridconnected wind energy system without storage. 


\section{REFERENCES}

[1] Shika. S, Bhatti. T. S and Kothari. D.P, Wind energy in India. Shifting paradigms and challenges ahead. J Energy Eng, 2004:67-74.

[2] Tina, G., Gagliano, S. and. Raiti, S. Hybrid solar/wind power system probabilistic modeling for long-term performance assessment, Solar Energy, 2006, Vol. 80, pp.578-588.

[3] H. Weigt, Germany's wind energy: The potential for fossil capacity replacement and cost saving. Applied Energy, 2009, Vol. 86, pp.1857-1863. [23] Celik, A. N, Optimization and techno-economic analysis of autonomous photovoltaic-wind hybrid energy systems in comparison to single photovoltaic and wind systems, Energy Conversion \& Management, 2002, Vol. 43, pp. 2453-2468.

[4] Aynur. U. A and Figen. B. B, Evaluation of wind energy potential and electricity generation at six locations in Turkey. Applied Energy, 2009, Vol. 86 pp.1864-1872.

[5] Fyrippis. I, Axaopoulos. P. J and Panayiotou. G, Wind energy potential assessment in Naxos Island, Greece. Applied Energy, 2010, Vol. 87, pp.577-586. [6] Keyhani. A, Varnamkhasti. M. Gh, Khanali. M and Abbaszadeh. R, An assessment of wind energy potential as a power generation source in the capital of Iran, Tehran. Energy, 2010, Vol. 35, pp.188-201 201.

[7] Sahin. B, Bilgili. M and Akilli. H, The wind power potential of the eastern Mediterranean region of Turkey, Journal of Wind Engineering and Industrial Aerodynamics, 2005, Vol.93, pp. 171-183.

[8] Zhoua.W, Yanga. H and Fang.Zh, Wind power potential and characteristic analysis of the Pearl River Delta region, China, Renewable Energy, 2006, Vol. 31, pp.739-753.

[9] Maaghooli D, An investigation on wind power and solar energy in Iran, Iran's atomic energy agency (New sources of energy), 1992.

[10]Wolde.G. W, Wind energy survey in Ethiopia, Solar and Wind Technology, 1988, 5(4):341-51.

\section{Creative Commons Attribution License 4.0 (Attribution 4.0 International, CC BY 4.0)}

This article is published under the terms of the Creative Commons Attribution License 4.0 https://creativecommons.org/licenses/by/4.0/deed.en_US 